\title{
Hybrid Liquid-Crystalline Block Copolymers \\ I. Synthesis and Mesomorphic Behavior of Polyester-Polymethacrylate Block Copolymers
}

\author{
Michele Laus, ${ }^{*}$ Maria Chiara Bignozzi,* Annino Sante Angeloni, ${ }^{*}$ \\ Oriano Francescangeli, ${ }^{* *}$ Giancarlo Galli, ${ }^{* * *}$ \\ and Emo CHIELlini $* * *,+$
}
* Dipartimento di Chimica Industriale e dei Materiali, Università di Bologna, Viale Risorgimento 4, 40136 Bologna, Italy
** Dipartimento di Scienze dei Materiali e della Terra, Università di Ancona, Via Brecce Bianche, 60131 Ancona, Italy
*** Dipartimento di Chimica e Chimica Industriale, Università di Pisa, Via Risorgimento 35, 56126 Pisa, Italy

(Received February 21, 1995)

\begin{abstract}
A new type of block copolymers comprising both main-chain and side-chain liquid-crystalline (LC) blocks in the same macromolecular structure was synthesized and studied. The former was a semiflexible LC polyester block, and the latter was an LC polymethacrylate block. Thermal, dynamic-mechanical, and X-ray diffraction data indicated that the two structurally different blocks were partly phase-separated in the glassy and LC states. Significant deviations of the transition temperatures and enthalpies were observed relative to those of the corresponding homopolymers.
\end{abstract}

KEY WORDS Block Copolymer / Liquid-Crystalline Copolymer / Polyester Block / Polymethacrylate Block / Phase Separation /

Very recently, great attention has been devoted to the synthesis and physical properties of liquid-crystalline (LC) block copolymers. ${ }^{1-12}$ Interest in these copolymers is basically related to their potential use as highly versatile interfacially active additives and melt-viscosity reducers potentially capable of providing enhanced optimization of materials performance. In addition, from a more fundamental standpoint, due to the equilibrium nature of the LC transitions, these new materials can be helpful in assessing specific aspects of polymer physics. On the one hand, block copolymers with LC segments may be model systems for semicrystalline block copolymers and new opportunities can be envisaged to obtain equilibrium relations between gross geometrical and topological patterns such as the dimension

\footnotetext{
$\dagger$ To whom all correspondence should be addressed.
}

and shape of the domain structure, including also the relevant interfacial contributions, and the molecular dimensions and interactions of the different blocks. On the other hand, these materials can be valuable in elucidating the influence exerted by the boundary conditions and finite domain size on the onset, nature and stability of the LC phases.

Different approaches to the preparation of block copolymers containing LC blocks include i) polymer-analog reactions on preformed block copolymers with narrow dispersity of block lengths ${ }^{1,3}$; ii) copolymerization of mesogenic monomers with non-mesogenic monomers by living or quasi-living techniques, such as the ring-opening metathesis, ${ }^{5}$ grouptransfer, ${ }^{2}$ anionic, ${ }^{4,12}$ and cationic ${ }^{11}$ polymerizations; iii) condensation of telechelics 


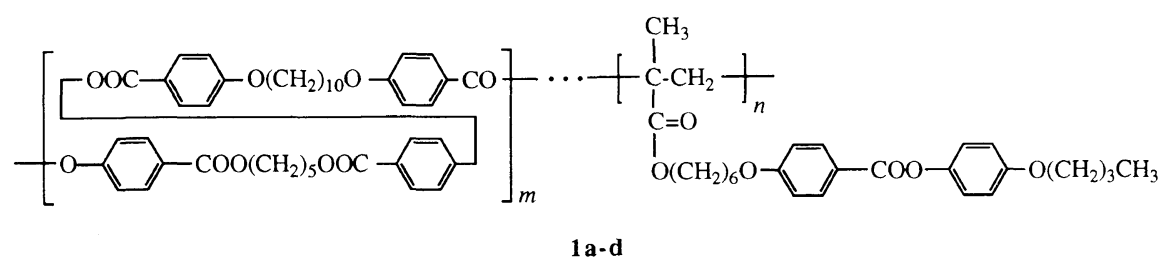

Figure 1. Simplified structure of block copolymers 1a-d.

bearing functional end groups ${ }^{6}$; and iv) the use of azo macroinitiators. ${ }^{7-10}$

By this last procedure, we have developed new block copolymers consisting of semicrystalline/side-chain LC blocks, ${ }^{7}$ amorphous/ main-chain LC blocks, ${ }^{8,9}$ or a combination of both main-chain and side-chain LC blocks. ${ }^{10}$ For the former two copolymer systems, the chemically different blocks appeared mutually immiscible thus producing multidomain structures in which the two blocks were strongly segregated. Even in the latter class of block copolymers, the different blocks were partially phase-separated in the glassy and LC phases. However, the glass transition behavior and the substantial deviations of the smectic-nematic and nematic-isotropic phase transition parameters of the main-chain block from those expected from the structurally analogous homopolymer suggested the existence of interactions between the main-chain and side-chain blocks like in a partially compatible system.

To extend the macromolecular architecture of this class of block copolymers and to further elucidate the peculiar role of the block length and block length distribution in determining the compatibility and phase-separation propensities of the chemically different blocks within the glassy and LC phases, this paper illustrates the synthesis and properties of a new class of block copolymers $\mathbf{1 a - d}$ comprising both main-chain and side-chain LC blocks (Figure 1). They were constituted by a mainchain LC polyester block (block A) and a side-chain LC polymethacrylate block (block B). The main-chain polyester homopolymer 2 exhibited nematic and smectic $\mathrm{C}$ meso-

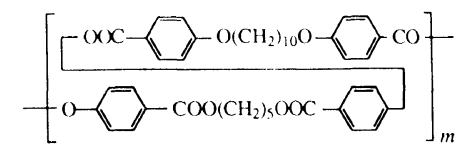

2

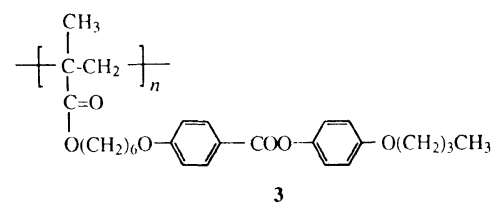

phases. ${ }^{13,14}$ The side-chain polymethacrylate homopolymer $\mathbf{3}$ formed nematic and smectic A mesophases. ${ }^{15}$

Therefore, one could anticipate finding enhanced interactions among the LC blocks in copolymers 1a-d incorporating simultaneously main-chain and side-chain blocks in one single macromolecule. In this paper we report on the synthesis and general mesophase behavior of block copolymers 1a-d. Their rather unique mesophase structure will be described in a following paper. ${ }^{16}$

\section{EXPERIMENTAL}

\section{Materials}

Decamethylene dioxydibenzoyl chloride $^{13}$ (4), 4, 4'-azobis(4-cyanopentanoyl chloride) ${ }^{17}$ (5), pentamethylene di(4-hydroxybenzoate $)^{13}$ (6), and 4-butoxyphenyl 4-(6-(methacryloyloxy)hexyloxy)benzoate ${ }^{15}$ (7) were prepared according to literature procedures. Macroinitiator $\mathbf{M}-\mathbf{C}_{5} \mathbf{C}_{10}$ and block copolymers $\mathbf{1 a}-\mathbf{d}$ were prepared according to the synthetic route illustrated in Scheme 1.

Macroinitiator $\boldsymbol{M}-\boldsymbol{C}_{5} \boldsymbol{C}_{10}: 1.85 \mathrm{~g}(4.10 \mathrm{mmol})$ of 4 and $0.13 \mathrm{~g}(0.410 \mathrm{mmol})$ of 5 were dissolved in $30 \mathrm{ml}$ of dichloroethane and the solution was 
transferred into an appropriate flask containing $1.55 \mathrm{~g}$ (4.51 mmol) of 6, $0.36 \mathrm{~g}(9.5 \mathrm{mmol})$ of $\mathrm{NaOH}$ and $0.2 \mathrm{~g}(0.56 \mathrm{mmol})$ of benzyl tributylammonium bromide (BTBAB) in $50 \mathrm{ml}$ of water at $0-5^{\circ} \mathrm{C}$. The mixture was vigorously stirred for $2 \mathrm{~min}$ and then poured into $300 \mathrm{ml}$ of methanol. The precipitated macroinitiator $\mathbf{M}-\mathbf{C}_{5} \mathbf{C}_{10}$ was purified by repeated precipitations from chloroform solution into methanol and dried $24 \mathrm{~h}$ in vacuo at room temperature. Yield: $64 \%$.

Block Copolymers $1 \boldsymbol{a}-\boldsymbol{d}$ : In a typical copolymerization reaction, the required amount of 7 and $0.4 \mathrm{~g}$ of the macroinitiator $\mathbf{M}-\mathbf{C}_{5} \mathbf{C}_{10}$ were dissolved in $10 \mathrm{ml}$ of anhydrous tetrahydrofuran. The reaction mixture was introduced into a Pyrex glass ampoule, freeze-thaw degassed and then sealed under vacuum. After reacting for $20 \mathrm{~h}$ at $70^{\circ} \mathrm{C}$, the copolymer was recovered by addition of a ten-fold excess of methanol and purified from oligomers by extraction with boiling methanol in a Kumagawa extractor. The copolymer was then dried in vacuo for $24 \mathrm{~h}$. The yield of copolymerization was in the $60-70 \%$ range.

Four copolymer samples were synthesized by the above procedure keeping constant the concentration of the macroinitiator and using different amounts of 7 in the feed mixture: $0.3 \mathrm{~g}, 1 \mathrm{a} ; 0.7 \mathrm{~g}, 1 \mathrm{~b} ; 1.0 \mathrm{~g}, 1 \mathrm{c} ; 2.0 \mathrm{~g}, 1 \mathrm{~d}$.

\section{Characterization}

${ }^{1} \mathrm{H}$ NMR and ${ }^{13} \mathrm{C}$ NMR spectra were recorded on a Varian Gemini 200 spectrometer. The composition of the copolymers was determined from the relevant ${ }^{1} \mathrm{H}$ NMR spectra. Average molecular weights were determined by size exclusion chromatography (SEC) of chloroform solutions with a 590 Waters chromatograph equipped with a Perkin Elmer UV detector using a Shodex KF-804 column. Polystyrene standard samples were empolyed for the SEC calibration. Differential scanning calorimetry (DSC) analyses were carried out under dry nitrogen flow with a Perkin-Elmer DSC 7 apparatus. The transition temperatures were taken from the DSC traces of samples annealed by cooling from the isotropic melt, as corresponding to the maximum/minimum of the enthalpic peaks at a heating/cooling rate of $10 \mathrm{~K} \mathrm{~min}^{-1}$. Optical microscopy observations were performed on polymer films between glass slides by means of a Reichert Polyvar microscope equipped with a programmable Mettler FP52 heating stage at a scanning rate of $10 \mathrm{~K} \mathrm{~min}^{-1}$. Dynamic-mechanical measurements were performed with a dynamic-mechanical analyzer (Perkin Elmer DMTA 7 at a scanning rate of $4 \mathrm{~K} \mathrm{~min}^{-1}$ ) at $1 \mathrm{~Hz}$ frequency. Samples were compression molded at $400 \mathrm{~K}$ for $15 \mathrm{~min}$ to form $\sim 1 \mathrm{~mm}$ thick sheets, and the three point bending geometry was used. X-ray diffraction measurements on powder samples were performed using the Inel CPS 120 powder diffractometer, equipped with a position sensitive detector covering $120^{\circ}$ in the scattering angle $2 \theta$, with an angular resolution of $0.018^{\circ}$ in $\theta$. $\mathrm{Ge}(111)$ monochromatized $\mathrm{Cu}-K_{\alpha}$ radiation was used. The sample, $\sim 1 \mathrm{~mm}$ thick, was placed between two thin $\mathrm{Al}$ sheets, fixed to an Al sample holder. Heating was achieved by a hot stage whose temperature was controlled within $\pm 0.1^{\circ} \mathrm{C}$ by an automatic temperature regulator. X-Ray diffraction patterns were recorded from room temperature up to the isotropization point.

\section{RESULTS AND DISCUSSION}

\section{Synthesis}

Block copolymers 1a-d were synthesized via two successive polycondensation and freeradical polymerizations as outlined in Scheme 1. The polyester macroinitiator $\mathbf{M}-\mathbf{C}_{5} \mathbf{C}_{10}$ was prepared by reacting equimolar amounts of the sodium of pentamethylene di(4-hydroxybenzoate) (6) and a mixture of 4,4'-decamethylene dioxydibenzoyl chloride (4) and 4,4'azobis(4-cyanopentanoyl chloride) (5) (10:1 by $\mathrm{mol})$ in the presence of a catalytic amount of a phase transfer agent (BTBAB). Subsequently, the macroinitiator $\mathbf{M}-\mathbf{C}_{5} \mathbf{C}_{10}$ was used as a 


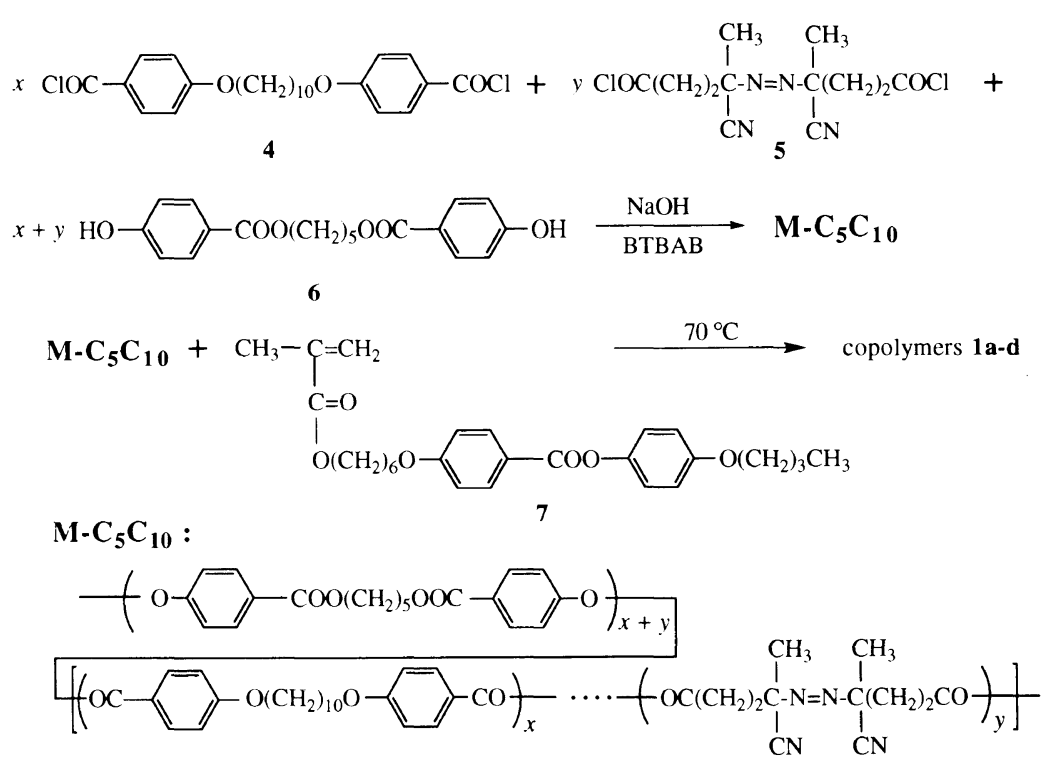

Scheme 1. Synthetic route for the preparation of block copolymers $1 \mathbf{1 a - d}$.

free-radical source to initiate the polymerization of methacrylate 7 through the thermal decomposition of the azo groups at $70^{\circ} \mathrm{C}$. Four block copolymers $1 \mathrm{a}-\mathbf{d}$ were prepared using different concentrations of the methacrylate monomer in the feed mixture (Table I). They were purified by repeated precipitations from chloroform solution into methanol and by extraction with boiling methanol to eliminate oligomers and unreacted monomers. The content of the polyester block ranged from 21 to $65 \mathrm{wt} \%$ (Table I). In addition, a sample of $\mathbf{M}-\mathbf{C}_{5} \mathbf{C}_{10}$ was thermally decomposed at $70^{\circ} \mathrm{C}$ in the presence of a large amount of 2,6-di-tertbutyl-4-methylphenol, as a radical scavenger, to avoid or at least reduce the recombination of the primary macroradicals generated. The resulting polyester $\mathbf{2}$ was taken as a model of the main-chain block in the copolymers.

The molecular weight characteristics of the polymers and copolymers were studied by SEC. All the SEC curves had a similar shape, but while the curve of $\mathbf{2}$ was shifted toward higher values along the elution volume scale with respect to that of macroinitiator $\mathbf{M}-\mathbf{C}_{5} \mathbf{C}_{10}$, those of copolymers 1a-d were shifted toward
Table I. Composition and molecular weight data of block copolymers $\mathbf{1 a}-\mathbf{d}$, macroinitiator $\mathbf{M}-\mathbf{C}_{5} \mathbf{C}_{10}$ and polyester $\mathbf{2}$

\begin{tabular}{|c|c|c|c|c|c|}
\hline \multirow{2}{*}{ Sample } & \multirow{2}{*}{$M_{n}^{\mathrm{b}}$} & \multirow{2}{*}{$M_{w} / M_{n}^{\mathrm{b}}$} & \multirow{2}{*}{$\frac{\begin{array}{c}\text { Polyester } \\
\text { block }^{\mathbf{a}}\end{array}}{\text { wt } \%}$} & \multicolumn{2}{|c|}{$\begin{array}{c}\text { Polymethacrylate } \\
\text { block }\end{array}$} \\
\hline & & & & $w t \%$ & $M_{n}^{\mathrm{b}}$ \\
\hline $1 \mathbf{a}$ & 18000 & 1.7 & 65 & 35 & 14000 \\
\hline $1 \mathrm{~b}$ & 21000 & 1.8 & 41 & 59 & 18000 \\
\hline 1c & 24000 & 2.0 & 33 & 67 & 21000 \\
\hline 1d & 33000 & 3.4 & 21 & 79 & 30000 \\
\hline$M-C_{5} C_{10}$ & $5400^{\mathrm{c}}$ & $2.4^{\mathrm{c}}$ & 100 & - & - \\
\hline 2 & $3400^{\mathrm{c}}$ & $2.0^{\mathrm{c}}$ & 100 & - & - \\
\hline
\end{tabular}

${ }^{\mathrm{a}}$ Content of polyester block in copolymers, homopolymer, or macroinitiator (by ${ }^{1} \mathrm{H}$ NMR). ${ }^{b}$ By SEC, with polystyrene calibration, unless indicated otherwise. ${ }^{\mathrm{c}} \mathrm{By}$ SEC, with universal calibration.

lower values (Figure 2). $M_{n}=5400$ and $M_{w} /$ $M_{n}=2.4$ for $\mathbf{M}_{-} \mathrm{C}_{5} \mathrm{C}_{10}$, and $M_{n}=3400$ and $M_{w} / M_{n}=2.0$ for 2 were found using the universal calibration method (Table I). An $M_{n}$ of 3200 was calculated for polyester 2 under the hypotheses that 4,4'-azobis(4-cyanopentanoyl chloride) (5) reacted quantitatively in the polycondensation reaction and distributed statistically along the polymer chain. ${ }^{9}$ This 


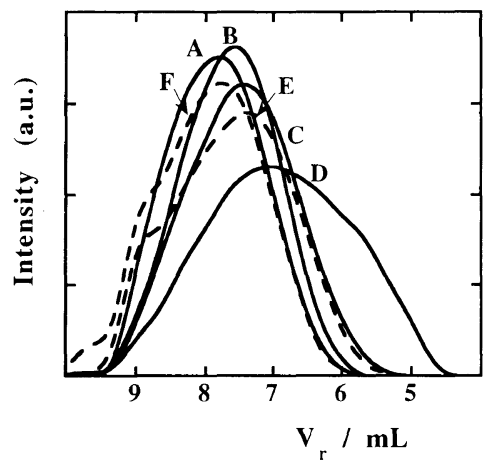

Figure 2. SEC curves of block copolymers 1a (A), 1b (B), 1c (C), 1d (D), macroinitiator $M-C_{5} C_{10}(E)$, and polyester $2(\mathrm{~F})$.

value is consistent with the experimental one. Accordingly, we estimate that macroinitiator $\mathbf{M}-\mathbf{C}_{5} \mathbf{C}_{10}$ contained on average one reactive azo group per polymer chain. Values of $M_{n}$ in the range 18000 to 33000 and $M_{w} / M_{n}$ comprised between 1.7 and 3.4 were evaluated for block copolymers by SEC using the polystyrene calibration curve (Table I). The molecular weight of the polyester block was constant (3400) throughout the series, while the molecular weight of the polymethacrylate block increased from 14000 for 1a to 30000 for 1 d.

It is well established that the free-radical polymerization of methacrylate monomers terminates ${ }^{18,19}$ by a disproportionation mechanism which, in the present polymerization system and from macroinitiator chains containing one reactive azo group, resulted in the formation of polyester (block A)/polymethacrylate (block B) AB diblock copolymers. However, any preference for a combination termination mechanism and the presence of more than one azo group in the polymer chain of the macroinitiator $\mathbf{M}-\mathbf{C}_{5} \mathbf{C}_{10}$ would yield ABA triblock and $(\mathrm{AB})_{n}$ multiblock copolymer structures.

\section{Dynamic-Mechanical Behavior}

The glass and subglass transitions of block copolymers 1a-d were studied by dynamicmechanical analysis (DMA) in the linear vis-
Table II. Transition temperatures ${ }^{\mathrm{a}}$ of block copolymers 1a-d, polyester $\mathbf{2}$, and polymethacrylate 3

\begin{tabular}{|c|c|c|c|c|c|c|c|}
\hline \multicolumn{2}{|c|}{ Sample } & \multicolumn{3}{|c|}{$\begin{array}{c}\text { Polyester } \\
\text { block (block A) }\end{array}$} & \multicolumn{3}{|c|}{$\begin{array}{c}\text { Polymethacrylate } \\
\text { bock (block B) }\end{array}$} \\
\hline Type & $\begin{array}{c}\text { Block A } \\
/ \mathrm{wt} \%\end{array}$ & $\begin{array}{l}T_{\mathrm{g}}^{\mathrm{b}} \\
/ \mathrm{K}\end{array}$ & $\begin{array}{c}T_{\mathrm{S}-\mathrm{N}} \mathrm{c} \\
/ \mathrm{K}\end{array}$ & $\begin{array}{c}T_{\mathrm{N}-1}{ }^{\mathrm{c}} \\
/ \mathrm{K}\end{array}$ & $\begin{array}{l}T_{\mathrm{g}}^{\mathrm{b}} \\
/ \mathrm{K}\end{array}$ & $\begin{array}{c}T_{\mathrm{S}-\mathrm{N}}{ }^{\mathrm{c}} \\
/ \mathrm{K}\end{array}$ & $\begin{array}{c}T_{\mathrm{N}-1}{ }^{\mathrm{c}} \\
/ \mathrm{K}\end{array}$ \\
\hline $1 \mathbf{a}$ & 65 & 304 & & 41 & 36 & nd & 384 \\
\hline lb & 41 & 317 & 401 & 42 & 363 & 36 & 387 \\
\hline 1c & 33 & 326 & 403 & 423 & 360 & 367 & 388 \\
\hline 1d & 21 & 329 & 404 & 424 & 362 & 372 & 389 \\
\hline 2 & 100 & 296 & 411 & 430 & - & - & - \\
\hline 3 & 0 & - & - & - & 366 & 372 & 382 \\
\hline
\end{tabular}

${ }^{\mathrm{a}} \mathrm{g}$, glassy; S, smectic (A or $\mathrm{C}$ ); $\mathrm{N}$, nematic; I, isotropic ${ }^{b}$ By DMA, at $1 \mathrm{~Hz}$ and $4 \mathrm{~K} \mathrm{~min}^{-1}$ scanning rate. ${ }^{\mathrm{c}}$ From the DSC cooling curve, at $10 \mathrm{~K} \mathrm{~min}^{-1}$ scanning rate. ${ }^{\mathrm{d}}$ Not detected by DSC.

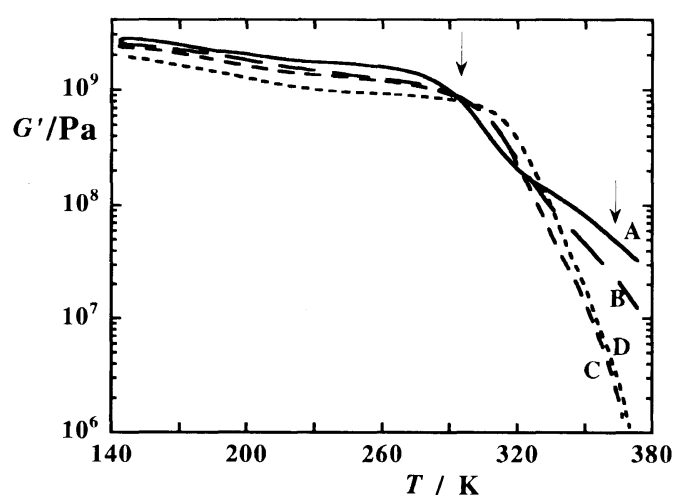

Figure 3. Trend of the dynamic storage modulus $\left(G^{\prime}\right)$ with temperature for block copolymers 1a (A), lb (B), 1c (C), and 1d (D) at $1 \mathrm{~Hz}$ (arrows indicate the glass temperatures of $\mathbf{1 a}$ ).

coelasticity range at $1 \mathrm{~Hz}$ frequency. The transition temperature of the relaxation processes was taken at the maximum of the relevant loss tangent peaks (Table II). The trends of the dynamic storage modulus $\left(G^{\prime}\right)$ (Figure 3 ) and loss tangent $(\tan \delta)$ (Figure 4$)$ as a function of temperature are very similar for all block copolymers. $G^{\prime}$ was about $4 \times 10^{9} \mathrm{~Pa}$ at $150 \mathrm{~K}$ for all samples and decreased progressively with increasing temperature. One minor relaxation was detected in the $170-230 \mathrm{~K}$ region, 
primarily due to local modes of relatively short chain segments of both main-chain and sidechain blocks. A marked drop of $G^{\prime}$, with a prominent peak in the relevent $\tan \delta$ curve, was observed between 290 and $310 \mathrm{~K}$ due to the glass transition of the main-chain block. In addition, a gradual decrease of the modulus in the temperature region between 330 and $370 \mathrm{~K}$ was due to the glass transition of the side-chain block. Above $380 \mathrm{~K}$, all the samples lost their dimensional stability.

The decrease of $G^{\prime}$ in two definite steps at the glass transitions of the polyester and polymethacrylate blocks was related to their weight fraction in the copolymer. The $T_{\mathrm{g}}$ of the polyester block decreased, whereas that of the

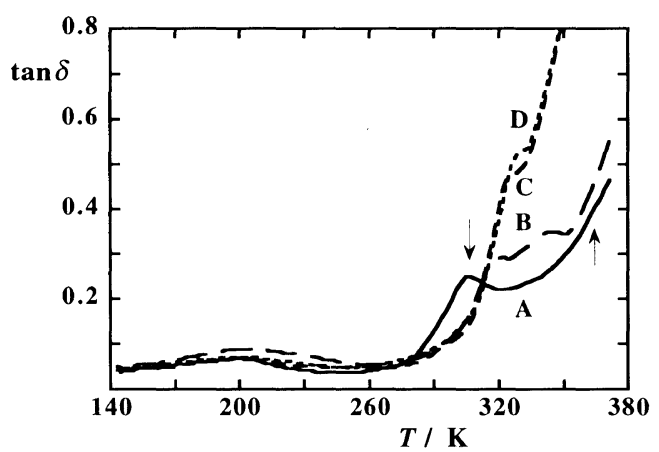

Figure 4. Trend of the loss tangent $(\tan \delta)$ with temperature for block copolymers 1a (A), 1 b (B), 1c (C), and 1d (D) at $1 \mathrm{~Hz}$ (arrows indicate the glass temperatures of 1a).

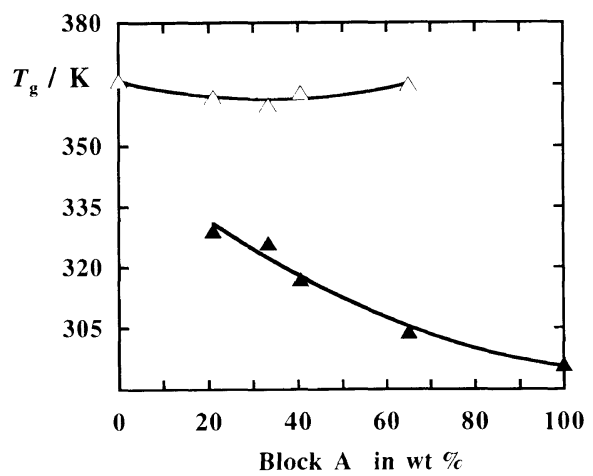

Figure 5. Trends of the glass transition temperatures of the polyester block $(\boldsymbol{\Delta})$ and polymethacrylate block $(\triangle)$ in block copolymers 1a-d as a function of the wt $\%$ content of polyester block (block A). polymethacrylate block remained practically constant with a slight increase as the amount of the main-chain block in the block copolymers increased (Figure 5). Thus, the evolution of the glass transition of the main-chain block with copolymer composition seemed a reliable monitor of the existence of interactions among the different blocks in the amorphous state. The occurrence of two distinct glass transition regions indicates a phase separation between the blocks. However, the width of the glass transition region of both main-chain and sidechain blocks and the variations in the relevant $T_{\mathrm{g}}$ reflect a certain degree of compatibility between the chemically different blocks. This should result in the formation of a somewhat diffuse interphase. The practical insensitivity of the $T_{\mathrm{g}}$ of the polymethacrylate block to copolymer composition may be attributed to two compensating opposite contributions, that is an increase due to an increase in $M_{n}$ of this block (Table I) and an anticipated decrease because of enhanced compatibility with the polyester block.

\section{Mesomorphic Behavior}

The phase transition temperatures and enthalpies of the block copolymers are collected in Tables II and III, along with those of polyester $\mathbf{2}$ and polymethacrylate $\mathbf{3}$ homopolymers

Table III. Transition enthalpies ${ }^{\mathrm{a}}$ of block copolymers $\mathbf{1 a - d}$, polyester $\mathbf{2}$, and polymethacrylate 3

\begin{tabular}{|c|c|c|c|c|c|}
\hline \multicolumn{2}{|c|}{ Sample } & \multicolumn{2}{|c|}{$\begin{array}{c}\text { Polyester } \\
\text { block (block A) }\end{array}$} & \multicolumn{2}{|c|}{$\begin{array}{c}\text { Polymethacrylate } \\
\text { block (block B) }\end{array}$} \\
\hline Type & $\begin{array}{c}\text { block A } \\
/ \mathrm{wt} \%\end{array}$ & $\begin{array}{l}\Delta H_{\mathrm{S}-\mathrm{N}}{ }^{\mathbf{a}} \\
/ \mathrm{J} \mathrm{g}^{-1}\end{array}$ & $\begin{array}{l}\Delta H_{\mathrm{N}-1}^{a} \\
/ \mathrm{Jg}^{-1}\end{array}$ & $\begin{array}{l}\Delta H_{\mathrm{S}-\mathrm{N}}{ }^{\mathrm{a}} \\
/ \mathrm{J} \mathrm{g}^{-1}\end{array}$ & $\begin{array}{l}\Delta H_{\mathrm{N}-\mathrm{I}}{ }^{a} \\
/ \mathrm{Jg}^{-1}\end{array}$ \\
\hline $1 \mathrm{a}$ & 65 & 1.1 & 0.3 & $\mathrm{nd}^{\mathrm{b}}$ & 1.1 \\
\hline $1 b$ & 41 & 1.2 & 0.4 & 0.5 & 1.7 \\
\hline 1c & 33 & 1.3 & 0.5 & 0.7 & 1.8 \\
\hline 1d & 21 & 2.0 & 0.7 & 1.5 & 2.7 \\
\hline 2 & 100 & 4.7 & 2.9 & - & - \\
\hline 3 & 0 & - & - & 3.0 & 2.8 \\
\hline
\end{tabular}

${ }^{\mathrm{a}} \mathrm{By} \mathrm{DSC}$, at $10 \mathrm{~K} \mathrm{~min}^{-1}$ scanning rate. S, smectic (A or C); N, nematic; I, isotropic. ${ }^{\mathrm{b}}$ Not detected by DSC. 
for comparison. The thermal behavior of block copolymers $1 \mathbf{1 a} \longrightarrow \mathbf{d}$ was derived from the DSC cooling curves, on account of the better resolution of the transition peaks. In each copolymer, they were qualitatively similar to those that are illustrated in Figure 6 for 1c. Polyester 2 was amorphous and exhibited an isotropic-nematic transition at $430 \mathrm{~K}$ and a nematic-smectic $\mathrm{C}$ transition at $411 \mathrm{~K}$ (Figure 6A). Polymethacrylate 3 was also amorphous and underwent isotropic-nematic and nematic smectic A transitions at 382 and $372 \mathrm{~K}$, respectively (Figure 6B). The DSC cooling curve (Figure 6C) of copolymer 1c showed four exothermic peaks centered at 423, 403, 388, and $367 \mathrm{~K}$. Comparison of this curve with those of 2 and $\mathbf{3}$ suggests that the former two transitions were due to the mesophase transitions of the main-chain block, whereas the latter two were associated to the mesophase transitions of the side-chain block.

The above attibution was also confirmed by $\mathrm{X}$-ray diffraction analysis. As a typical example, Figure 7 reports the X-ray powder patterns of $\mathbf{1 a}$ at different temperatures, after the sample had been annealed by cooling from the isotropic melt. At room temperature, the X-ray diagram (Figure 7B) consisted of two small-angle reflections, originated from layer periodicities of $20.0 \AA\left(d_{1}\right)$ and $29.0 \AA\left(d_{2}\right)$, and a wide-angle signal corresponding to a mean intermolecular distance $(D)$ of $4.6 \AA$. Very similar spectra were recorded for $\mathbf{1 b}, \mathbf{1 c}$, and 1d, for which only slight differences in the intensity ratios of the two small-angle reflections were noted, without modifications of the angular peak positions. No correlation exists between the signals with periodicities $d_{1}$ and $d_{2}$. The former corresponds exactly to the layer spacing of the smectic $\mathrm{C}$ mesophase of polyester 2 (Figure 7E), and the latter to the layer spacing of the smectic A mesophase of polymethacrylate 3 (Figure 7A). Therefore, the main-chain and the side-chain blocks were at least partly phase-separated and gave rise to two coexisting disordered smectic (A or C) mesophases with different layer periodicities. The small-angle peak at $d_{2}$ disappeared at temperatures above $370 \mathrm{~K}$ at the smecticnematic transition of the side-chain block, and the diagram was then consistent with the presence of the smectic mesophase of the mainchain block (Figure 7C). Above $400 \mathrm{~K}$, the small-angle peak at $d_{1}$ also vanished (Figure 7D), indicating the transition to the nematic mesophase of the main-chain block. The above trend of the X-ray diffraction patterns was completely reproducible in successive heating and cooling cycles. Detailed X-ray diffraction studies on mechanically and magnetically oriented samples are in progress to characterize

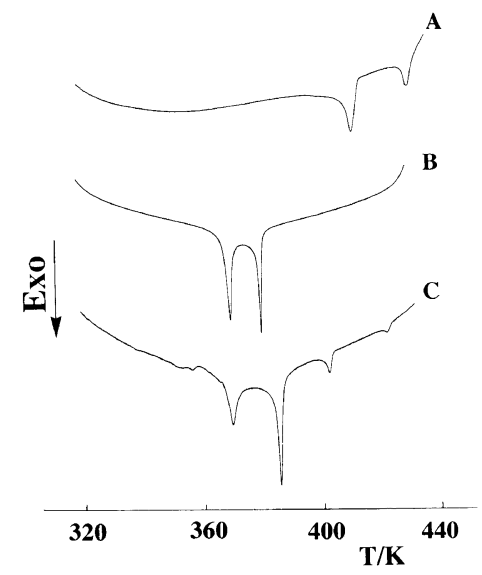

Figure 6. DSC second cooling curves $\left(10 \mathrm{~K} \mathrm{~min}^{-1}\right)$ for polyester 2 (A), polymethacrylate 3 (B), and block copolymer 1c (C).

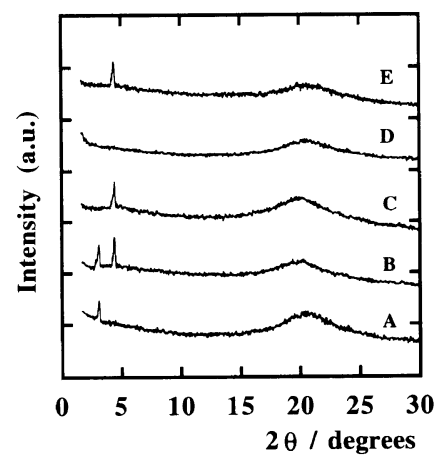

Figure 7. $\mathrm{X}$-Ray diffraction diagrams for polymethacrylate 3 at $300 \mathrm{~K}$ (A), block copolymer 1a at $298 \mathrm{~K}$ (B), $373 \mathrm{~K}$ (C), and $403 \mathrm{~K}$ (D), and polyester 2 at $376 \mathrm{~K}$ (E). 
the fine structure of the two smectic mesophases. When observed at the polarizing microscope, the copolymer samples did not exhibit specific optical textures and no information on their mesophase nature could be gained by this technique.

Figure 8 illustrates the trends of various mesophase transition temperatures of the polyester and polymethacrylate blocks as a function of the polyester block content in the copolymers. The transition temperatures of the main-chain block displayed a minimum at a composition of about $70 \mathrm{wt} \%$, whereas a not very pronounced maximum in the transition temperatures of the side-chain block was observed at a composition of about $20 \mathrm{wt} \%$.

The enthalpies of both the smectic-nematic and nematic-isotropic transitions of the polymethacrylate block, after normalization for the copolymer composition, decreased gradually with increasing content of the polyester block in the copolymers (Figure 9). However, well defined minima in the normalized enthalpies of both the smectic-nematic and nematic-isotropic transitions of the polyester block were detected at a polyester composition of about $50 \mathrm{wt} \%$. These results suggest the existence of partial miscibility between the two chemically different blocks. In addition, mutual disordering effects of the blocks might also contribute to lowering the transition enthalpies.

In previous papers, ${ }^{7-9}$ we have shown that in various $\mathrm{LC}$ block copolymers containing $\mathrm{LC}$ and non-LC blocks neither the temperature nor the enthalpy of the different mesophase transitions were affected to any significant extent by block copolymer composition in agreement with an essentially incompatible nature of the two blocks. They in fact underwent their individual phase transitions practically independent of each other. In contrast, in block copolymers comprising both main-chain and side-chain LC blocks the two structurally different blocks were partly phase-separated within the glassy and LC states. ${ }^{10}$ In particular, the nematic-isotropic transition temperature of the main-chain block was definitely higher than that of the relevant homopolymer. Moreover, the smectic-nematic and nematic-isotropic transition enthalpies of the main-chain block were substantially lower than those computed on the basis of the chemical composition of the copolymer. The partial compatibility of the two chemically different blocks observed in the present main-chain side-chain block copolymers matches the one of the previous copolymer system. However, in the present block copolymers, a decrease of stabil-

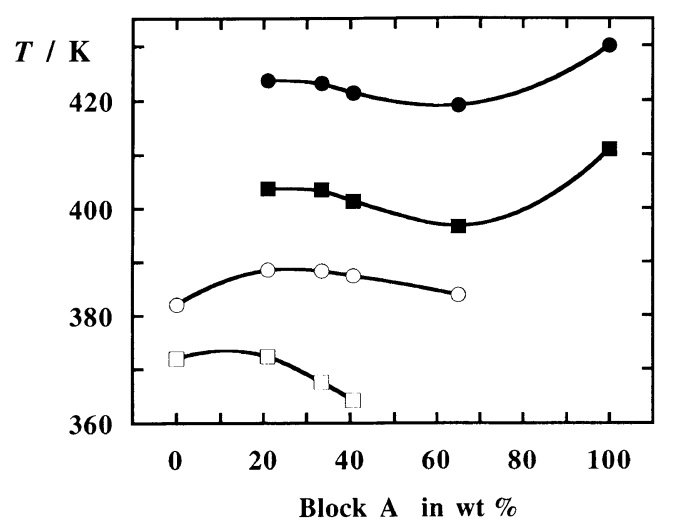

Figure 8. Trends of the transition temperatures of block copolymers 1a-d as a function of the wt $\%$ content of polyester block (block A): smectic-nematic ( $\square$ ) and nematic-isotropic (○) (polyester block); smectic-nematic ( $\square$ ) and nematic-isotropic $(O)$ (polymethacrylate block).

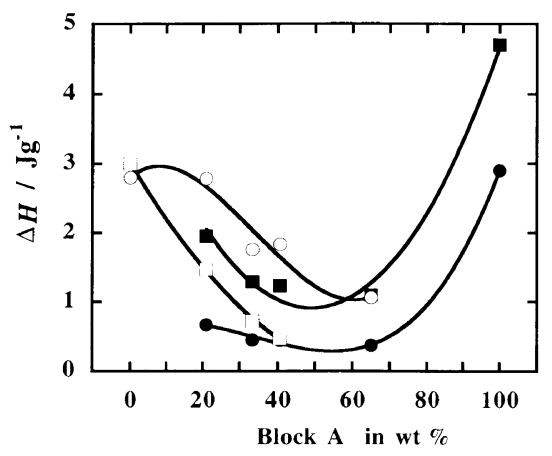

Figure 9. Trends of the normalized transition enthalpies of block copolymers 1a-d as a function of the wt $\%$ content of polyester block (block A): smectic-nematic ( $\mathbf{\square})$ and nematic-isotropic (O) (polyester block); smectic-nematic $(\square)$ and nematic-isotropic $(\bigcirc)$ (polymethacrylate block). 
ity of the smectic and nematic mesophases of the main-chain block is observed in contrast to the increase in the mesophase stability detected for the previous series.

\section{CONCLUSIONS}

We have synthesized and studied a series of block copolymers comprising both main-chain and side-chain LC blocks within the same polymer structure. Thermal and dynamicmechanical data show that the two chemically different blocks are at least partly phaseseparated in the glassy and LC phases and undergo distinct transitions, which could also be monitored by X-ray diffraction measurements. However, the significant deviations of the phase transition parameters of both blocks from those expected from the structurally analogous homopolymers indicate the existence of partial miscibility between the mainchain and side-chain blocks thus possibly producing an interphasic region. The stability of the LC phase of both the main-chain and side-chain blocks is lower than that of the corresponding homopolymers. This is in contrast to the behavior observed for other main-chain/side-chain block copolymers ${ }^{10}$ in which an increase in the stability of the LC phase generated by the main-chain block was detected. Therefore, no general statements may yet be made on the role of the block length and block length distribution as well as of the nature and stability of the LC phases in determining the compatibility and phaseseparation propensity of the chemically different blocks within the glassy and LC phases, or their influence on the onset and stability of the relevant mesophases. A systematic investigation on similar main-chain/side-chain block copolymer systems, by keeping constant the main-chain block structure and changing the chemical structure and length of the side-chain block, is presently under way.

Acknowledgment. This work was sup- ported from the Ministero dell'Università e della Ricerca Scientifica e Tecnologica of Italy.

\section{REFERENCES}

1. a) J. Adams and W. Gronski, Makromol. Chem., Rapid Commun., 10, 553 (1989); b) J. Adams, J. Sänger, C. Tefehne, and W. Gronski, Macromol. Chem., Rapid Commun., 15, 879 (1994).

2. M. Hefft and J. Springer, Makromol. Chem., Rapid Commun., 11, 397 (1990).

3. a) B. Zaschke, W. Frank, H. Fischer, K. Schmutzler, and M. Arnold, Polym. Bull. (Berlin), 27, 1 (1991); b) M. Arnold, S. Poser, H. Fischer, W. Frank, and H. Utschick, Macromol. Chem., Rapid Commun., 15, 487 (1994).

4. T. Kodaira and K. Mori, Makromol. Chem., 193, 1331 (1992).

5. Z. Komiya and R. R. Schrock, Macromolecules, 26, 1387 (1993).

6. L. H. Radzilowski, J. L. Wu, and S. I. Stupp, Macromolecules, 26, 879 (1993).

7. G. Galli, E. Chiellini, Y. Yagci, E, I. Serhatli, M. Laus, A. S. Angeloni, and M. C. Bignozzi, Makromol. Chem., Rapid Commun., 14, 185 (1993).

8. A. S. Angeloni, M. C. Bignozzi, M. Laus, E. Chiellini, and G. Galli, Polym. Bull. (Berlin), 31, 387 (1993).

9. E. Chiellini, G. Galli, A. S. Angeloni, M. Laus, M. C. Bignozzi, Y. Yagci, and E. I. Serhatli, Macromol. Symp., 77, 349 (1994).

10. G. Galli, E. Chiellini, M. Laus, M. C. Bignozzi, A. S. Angeloni, and O. Francescangeli, Macromol. Chem. Phys., 195, 2247 (1994).

11. a) V. Percec and M. Lee, J. Macromol. Sci., Pure Appl. Chem., A29, 723 (1992); b) G. Galli, E. Chiellini, M. C. Bignozzi, A. S. Angeloni, and M. Laus, Preprints, 35th IUPAC International Symposium on Macromolecules, Akron, OH (U.S.A.), 1994, p 270.

12. R. Bohnert and H. Finkelmann, Macromol. Chem. Phys., 195, 689 (1994).

13. E. Chiellini, G. Galli, M. Laus, A. S. Angeloni, O. Francescangeli, and B. Yang, J. Mater. Chem., 2, 449 (1992).

14. O. Francescangeli, B. Yang, G. Albertini, A. S. Angeloni, M. Laus, E. Chiellini, and G. Galli, Liq. Cryst., 3, 353 (1993).

15. R. Zentel and H. Ringsdorf, Makromol. Chem., Rapid Commun., 5, 393 (1984).

16. O. Francescangeli, M. Laus, M. C. Bignozzi, A. S. Angeloni, G. Galli, and E. Chiellini, Polym. J. (Jpn.), in press; $c f$. following paper, Part 2.

17. Y. Yagci, Polym. Commun., 26, 7 (1985).

18. W. Heitz, Makromol. Chem., Macromol. Symp., 10/11, 297 (1987).

19. G. C. Eastmond, Makromol. Chem., Macromol. Symp., 10/11, 71 (1987). 